\title{
Cytoplasmic Mineralocorticoid Receptor Expression Predicts Dismal Local Relapse-free Survival in Non-triple-negative Breast Cancer
}

\author{
ANNIINA JÄÄSKELÄINEN ${ }^{1,2}$, ARJA JUKKOLA ${ }^{3}$, KIRSI-MARIA HAAPASAARI ${ }^{2}$, \\ PÄIVI AUVINEN ${ }^{4}$, YLERMI SOINI ${ }^{2,5}$ and PEETER KARIHTALA ${ }^{1}$ \\ ${ }^{1}$ Department of Oncology and Radiotherapy, Medical Research Center Oulu, \\ Oulu University Hospital and University of Oulu, Oulu, Finland; \\ ${ }^{2}$ Department of Pathology, Medical Research Center, Oulu University Hospital, Oulu, Finland; \\ ${ }^{3}$ Department of Oncology, Tampere University Hospital, \\ Faculty of Medicine and Health Technology, University of Tampere, Tampere, Finland; \\ ${ }^{4}$ Department of Oncology and Cancer Center, Kuopio University Hospital, \\ and Institute of Clinical Medicine, University of Eastern Finland, Kuopio, Finland; \\ ${ }^{5}$ Department of Pathology, Kuopio University Hospital, University of Eastern Finland, Kuopio, Finland
}

\begin{abstract}
Background/Aim: The aim of the study was to investigate the prognostic role of androgen receptor $(A R)$, mineralocorticoid receptor $(M R)$ and glucocorticoid receptor $\beta$ (GR $\beta)$ expression in HER-2 negative breast cancer patients. Materials and Methods: The study population $(n=152)$ was enriched with triple-negative breast cancers (TNBC) $(n=96 ; 63.2 \%)$. The median follow-up time was 100 months. AR, MR and GR $\beta$ immunocytochemical staining was compared with that of epithelial-mesenchymal transition (EMT) markers (vimentin, SIP1, ZEB1). Results: High expression of cytoplasmic MR was associated with dismal local relapse-free survival $(R R=13.923 ; 95 \% C I=1.071$ $181.045 ; p=0.044)$ in tumours with non-TNBC phenotype. $A R$ and GR $\beta$ were more frequently expressed in $E R+/ P R+/ H E R 2-$ tumours, while cytoplasmic MR was more often expressed in TNBC tumours (for all, $p<0.0005$ ). GR $\beta$ and $A R$ were associated with decreased vimentin expression $(p<0.005)$, indicating their association with attenuated EMT. Conclusion: Cytoplasmic MR expression is a strong
\end{abstract}

This article is freely accessible online.

Correspondence to: Peeter Karihtala, MD, Ph.D., Department of Oncology and Radiotherapy, Medical Research Center, Oulu University Hospital and University of Oulu, P.O. Box 22, 90029 Oulu, Finland. Tel: +35 883152011, e-mail: peeter.karihtala@oulu.fi, ORCID ID 0000-0003-3490-3702

Key Words: Breast cancer, steroid receptor, mineralocorticoid receptor, immunohistochemistry, prognosis. predictor of local recurrence in non-metastatic breast cancer patients with non-TNBC tumour phenotype.

The expression of oestrogen (ER) and progesterone receptors (PR) and amplification of human epidermal growth factor receptor 2 (HER2) are important prognostic and predictive factors in breast cancer (1). Moreover, androgen receptor (AR), mineralocorticoid receptor (MR) and glucocorticoid receptor $\beta$ (GR $\beta$ ) belong to the nuclear receptor superfamily of transcription factors $(2,3)$. AR is expressed in $70-90 \%$ of all breast cancers, with a varying expression being reported in TNBC (4-7). The impact of AR in the pathogenesis of TNBC appears to be substantial and AR-positive TNBC forms a unique luminal androgen receptor (LAR) subtype. In relation to breast cancer, less is known about the two other steroid nuclear receptors (SNRs): MR and GR $\beta$.

$\mathrm{MR}$, being a part of the renin-angiotensin-aldosteronesystem (RAAS), regulates the physiological sodium and potassium balance and water excretion leading to blood pressure control. It is expressed in both epithelial and nonepithelial tissues, where it binds mainly aldosterone, but also in other mineralocorticoids or glucocorticoids (GC) depending on the expression of $11 \beta$-hydroxysteroid dehydrogenase $2(8$, 9). MR is localized in the cytosol in its inactive state, but its expression between the nuclear and the cytoplasmic localization varies, depending on ligands and other factors (10, 11). Considering the newer suggestions for DNA-binding sites, MR and GR both bind glucocorticoid receptor element (GRE) for regulating of gene expression $(12,13)$. There is also a significant cross-talk between glucocorticoids, mineralocorticoids and PR that has been suspected to be 
important in breast pathology (12). MR expression has been reported in certain breast cancer cell lines and some evidence suggests that it may be required for focal adhesion and ductal differentiation of breast cells $(12,14)$.

The GR has five isoforms, out of which, GR $\alpha$ and GR $\beta$ are the most well-known $(15,16)$. GR $\beta$ contains 742 amino acids of which the first 727 amino acids from the $\mathrm{N}$-terminus are identical with GR $\alpha$ (15). The physiologically predominant form, $\mathrm{GR} \alpha$, is mainly responsible for the classical GC-mediated effects, such as the control of stress-related homeostasis, proper organ function, and the immune/inflammatory response (17, 18). The studies about breast cancer and the GR have mainly focused on GR $\alpha$ or they have not specified the GR isoform, yet new evidence on the role of GR $\beta$ in breast cancer biology is emerging (19-23). GR $\beta$ does not bind GCs and its transcriptional activity is indirect and suppressive compared to $\mathrm{GR} \alpha$ (24). It is expressed ubiquitously, both in the cytoplasm and nuclei of human cells $(25,26)$.

Epithelial-mesenchymal transition (EMT) is physiologically active during wound healing and embryonic development, but it also promotes breast cancer invasion and metastasis (27). EMT can be indirectly assessed by evaluating the expression of proteins such as Zinc finger E-box-binding protein 1 (ZEB1), Smad Interacting Protein 1 (SIP1) and vimentin. ZEB1 and SIP1 are EMT-promoting transcription factors with zinc finger domains in their molecular structure (28-30). Vimentin is a cytoskeleton protein participating in the migration of epithelial cells and is also an indicator of ongoing EMT (31). EMT marker expression also notably differs in TNBC and non-TNBC (32).

Although AR expression is well characterized in both ERpositive and ER-negative breast cancers, the role of MR and GR $\beta$ expressions in breast cancer and carcinogenesis are less well-known. In the light of current evidence, the relationship between SNR expression and EMT is significant for breast cancer biology (33). This is the first time that MR and GR $\beta$ expression have been studied in breast cancer patients. We also connected in our data AR, MR and GR $\beta$ to EMT immunostainings, which were previously assessed. We enriched the cohort with TNBCs to evaluate more specifically the crosstalk between ER/PR and other steroid hormone receptors (33, 34). Based on in vitro models, we hypothesized that the biological and prognostic significance of steroid hormone receptors could differ in TNBC compared with non-TNBC.

\section{Materials and Methods}

Patients. The study population consisted of 152 breast cancer patients from Oulu and Kuopio University Hospitals (Table I). The patient data was retrospectively collected from the archives of Oulu and Kuopio University Hospitals based on the diagnosis and availability of tissue. Median follow-up period was 100.0 months (mean 95.8 months). Tumours and patients were assessed using histopathological classification and TNM classification according to the WHO $(35,36)$. Triple-negative breast carcinomas were defined
Table I. Patient characteristics.

\begin{tabular}{|c|c|}
\hline & $\mathrm{N}(\%)$ \\
\hline $\mathrm{T}$ class & $152(100 \%)$ \\
\hline $\mathrm{T} 1$ & $58(38.2 \%)$ \\
\hline $\mathrm{T} 2$ & $84(55.3 \%)$ \\
\hline $\mathrm{T} 3$ & $7(4.6 \%)$ \\
\hline $\mathrm{T} 4$ & $3(2.0 \%)$ \\
\hline $\mathrm{N}$ class & $152(100 \%)$ \\
\hline No & $79(52.0 \%)$ \\
\hline N1 & $53(34.9 \%)$ \\
\hline $\mathrm{N} 2$ & $14(9.2 \%)$ \\
\hline N3 & $6(3.9 \%)$ \\
\hline $\mathbf{M}$ class & $152(100 \%)$ \\
\hline M0 & $152(100 \%)$ \\
\hline M1 & $0(0 \%)$ \\
\hline Breast cancer type & $152(100 \%)$ \\
\hline TNBC & $96(63.2 \%)$ \\
\hline Non-TNBC & $56(36.8 \%)$ \\
\hline Histopathology & $152(100 \%)$ \\
\hline Ductal & $136(89.5 \%)$ \\
\hline Lobular & $2(1.3 \%)$ \\
\hline Medullary & $9(5.9 \%)$ \\
\hline Tubular & $1(0.7 \%)$ \\
\hline Other & $4(2.6 \%)$ \\
\hline Histopathological grade & $152(100 \%)$ \\
\hline Grade 1 & $4(2.6 \%)$ \\
\hline Grade 2 & $26(17.1 \%)$ \\
\hline Grade 3 & $122(80.3 \%)$ \\
\hline ER status & $152(100 \%)$ \\
\hline Negative $(<9 \%)$ & $96(63.2 \%)$ \\
\hline Weak $(10-29 \%)$ & $5(3.3 \%)$ \\
\hline Moderate $(30-59 \%)$ & $8(5.3 \%)$ \\
\hline High $(>59 \%)$ & $43(28.3 \%)$ \\
\hline PR status & $152(100 \%)$ \\
\hline Negative $(<9 \%)$ & $96(63.2 \%)$ \\
\hline Weak $(10-29 \%)$ & $11(7.2 \%)$ \\
\hline Moderate $(30-59 \%)$ & $11(7.2 \%)$ \\
\hline $\operatorname{High}(>59 \%)$ & $34(22.4 \%)$ \\
\hline HER2 status & $152(100 \%)$ \\
\hline HER2-positive (CISH) & $0(0 \%)$ \\
\hline HER2-negative & $152(100 \%)$ \\
\hline Ki67 status & $152(100 \%)$ \\
\hline Negative $(<5 \%)$ & $6(3.9 \%)$ \\
\hline Weak $(5-14 \%)$ & $22(14.5 \%)$ \\
\hline Moderate $(15-30 \%)$ & $26(17.1 \%)$ \\
\hline High $(>30 \%)$ & $47(30.9 \%)$ \\
\hline Not available & $51(33.6 \%)$ \\
\hline Local relapse & $152(100 \%)$ \\
\hline No local relapse & $140(92.1 \%)$ \\
\hline Local relapse & $12(7.9 \%)$ \\
\hline The site of 1 st distant metastasis & $152(100 \%)$ \\
\hline No distant metastases & $108(92.1 \%)$ \\
\hline Bone metastases & $9(5.9 \%)$ \\
\hline Lung metastases & $7(4.6 \%)$ \\
\hline Liver metastases & $3(2.0 \%)$ \\
\hline Multiple metastases & $19(12.5 \%)$ \\
\hline Other distant metastases & $6(4.0 \%)$ \\
\hline
\end{tabular}


as tumours with negative ER, PR and HER2 expression. Ninety-six $(63.2 \%)$ of the cases were of TNBC phenotype and 56 (36.8\%) of $\mathrm{ER}^{+} / \mathrm{PR}^{+} / \mathrm{HER} 2^{-}$(non-TNBC) phenotype.

Immunohistochemistry for ER, PR, Ki-67 and HER2 gene amplification status. TNBC and non-TNBC subtypes were confirmed with immunohistochemistry (IHC) on surgically removed tumours at the Departments of Pathology at Oulu and Kuopio University Hospitals. The formalin-fixed specimens were embedded in paraffin blocks and stored at the Departments of Pathology in Oulu and Kuopio. The expression levels of nuclear ER, PR and Ki67 were analysed as previously described (37). Tumours expressing nuclear ER or PR in more than $10 \%$ of malignant tumour cells were considered as ER/PR receptor-positive. If a specimen was found by IHC to be positive for membranous HER2 $(1+$ to $3+$ on a scale of 0 to $3+$ ), chromogenic in situ hybridization was used to determine HER2 gene amplification status. Specimens considered as HER2positive showed six or more gene copies of HER2 in the cells (38).

Immunohistochemistry and $A R, M R$ and $G R \beta$ expression assessment. Expression was recorded only in malignant cells. Cytoplasmic intensity was divided into four categories: 0 (negative), 1 (weakly positive), 2 (moderately positive), or 3 (strongly positive). The number of stained tumour cells was reported as percentage (0100). For a linear comparison of the data, an $\mathrm{H}$ score, that is a histological sum score, was calculated for each sample by multiplying the intensity with the percentage (39). All samples received an $\mathrm{H}$ score between 0-300.

The staining for AR, MR and GR $\beta$ was performed at the Department of Pathology, Oulu University Hospital according to the laboratory's routine protocols. The paraffin-embedded tissue blocks were cut into sections of $3 \mu \mathrm{m}$, placed on microscope slides, and de-paraffinized in xylene for three times of three min. Then, sections were rehydrated using graded alcohol solutions and subsequently rinsed in distilled water.

For AR and MR, antigen retrieval was performed using TrisEDTA buffer (Merck KGaA, Darmstadt, Germany; VWR international, Leuven, Belgium; respectively) ( $\mathrm{pH} 9.0$ ). The sections were heated in a microwave, first for two min $(800 \mathrm{~W})$ and then for $15 \mathrm{~min}(150 \mathrm{~W})$. Then, the AR and MR slides were cooled at room temperature for $20 \mathrm{~min}$ and rinsed in distilled water and phosphatebuffered saline with TWEEN (PBS-TWEEN) (Fisher Scientific, Loughborough, UK; Merck KGaA, Darmstadt, Germany; respectively). The endogenous peroxidase was neutralized in all AR, MR and GR $\beta$ sections with a blocking solution (Dako S2023, Dako Denmark, Glostrup, Denmark); a five-minute incubation time was applied. For AR and MR, two PBS-TWEEN washes of five min were performed. The AR and MR slides were incubated for $30 \mathrm{~min}$ at room temperature with the monoclonal anti-AR (Leica Biosystems Novocastra NCL-AR-318, Newcastle, UK) or anti-MR (Invitrogen Mineralocorticoid Receptor antibody HIOE4C9F, Rockford IL, USA) antibodies (dilutions 1:50 for AR, 1:000 for MR). AR and MR slides were washed with PBS-TWEEN, incubated with the EnVision ${ }^{\mathrm{TM}}$-polymer (DAKO K5007, Dako Denmark) for $30 \mathrm{~min}$ and washed again with PSB-TWEEN.

Regarding GR $\beta$, after de-paraffinizing, a second blocking step was performed with bovine serum albumin (BSA; Sigma A-3059, Steinheim, Germany) and phosphate-buffered saline (PBS, Fisher Scientific, Loughborough, UK) solution for $30 \mathrm{~min}$ at room temperature. The BSA-PBS solution was trickled from the slides, and the primary antibody (Invitrogen GR $\beta$ PA3-514, Rockford IL, USA; dilution 1:1000) was applied. The sections were incubated for two hours at room temperature and left overnight to $+4^{\circ} \mathrm{C}$. Then, the GR $\beta$ slides were returned to room temperature for two h, washed with PBS solution for ten min and a secondary antibody (Invitrogen biotinylated anti-rabbit IgG BA-1000, Vector Laboratories Inc., Burlingame, CA, USA) was applied. The sections were incubated for $30 \mathrm{~min}$ at room temperature. Following a ten-min wash with PBS, the ABC-complex (VECTASTAIN ${ }^{\circledR}$ ABC kit, Elite PK 6100 standard, Vector Laboratories Inc., Burlingame, CA, USA) diluted to $5 \mathrm{ml}$ of $0.5 \mathrm{M} \mathrm{NaCl}$-PBS buffer solution was added. The sections were incubated for $30 \mathrm{~min}$ at room temperature and washed with PBS for $10 \mathrm{~min}$.

For AR, MR and GR $\beta$ the colour was developed by incubating for 5 min with diaminobenzidine working solution (DAKO K5007 Dako Denmark), after which a rinse with distilled water was performed. The staining was completed by counterstaining the tissue sections with Mayer's haematoxylin (Reagena, Toivala, Finland). Then, the sections were rinsed, dehydrated, cleared and mounted. The methods and results concerning EMT marker immunostaining and assessment in this cohort have been reported earlier (32).

Ethics approval. The local ethics committee of the Hospital District of Northern Ostrobothnia (144/2011, amendment 23.2.2015) and the Finnish National Supervisory Authority for Welfare and Health (1339/05.01.00.06/2009) approved the study design. Following approval from the ethics committee of the Hospital District of Northern Ostrobothnia, written informed consent was not obtained from the patients at the time of sample donation.

Statistical analysis. Statistical analysis was carried out by using IBM ${ }^{\circledR}$ SPSS ${ }^{\circledR}$ Statistics software, v. 25.0.0.0 (IBM Corporation, Armonk, NY, USA). The significance of associations was assessed by using the Mann-Whitney $U$-test. Correlations between AR, MR and GR $\beta$ expression were analysed by using the Spearman correlation test. Established prognostic factors were re-formatted as two-class variables for the analyses. T-class was divided into T1 or T2-4 classes, and nodal status to either N0 or N1-3. The histopathological grade was divided into either grade 1-2 or grade 3 . Survival was analysed by using Kaplan-Meier curves with the log-rank test. The H-score median of AR, MR and GR $\beta$ expression was used as cut-off value in survival. For AR and GR $\beta$ expression the median was a division between positive and negative expressions, and for MR an $\mathrm{H}$-score 15 was the median. Overall survival (OS) was calculated from the date of the operation to the time of death from any cause. Relapse-free survival (RFS) was calculated from the date of the operation to the date of the first confirmed local relapse, either ipsilateral or contralateral in axilla, scar or breast. Breast cancer-specific survival (BCSS) was calculated from the date of the operation to the time of death due to breast cancer. Distant disease-free survival (DDFS) was calculated from the date of the operation to the date of the first confirmed distant relapse. For multivariate analyses Cox multivariate regression analysis (co-variates T-class and N-class) was used. Probability of less than 0.05 was considered significant in all analyses.

\section{Results}

Expression pattern. Of 152 patients in total, nuclear AR expression was reliably assessed in 139 (91.4\%) cases and cytoplasmic AR expression in 135 (88.8\%) cases. AR 

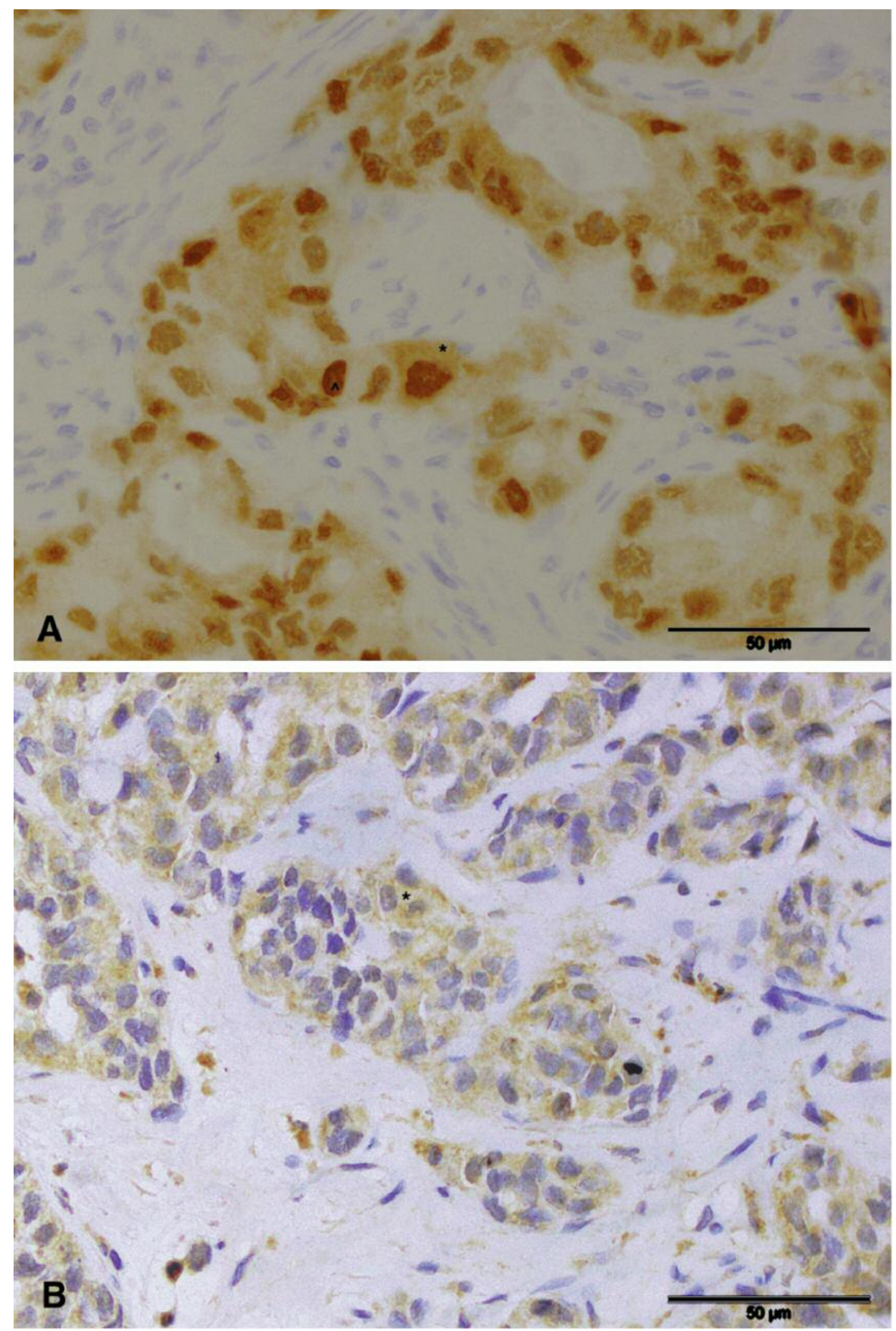

Figure 1. Continued 


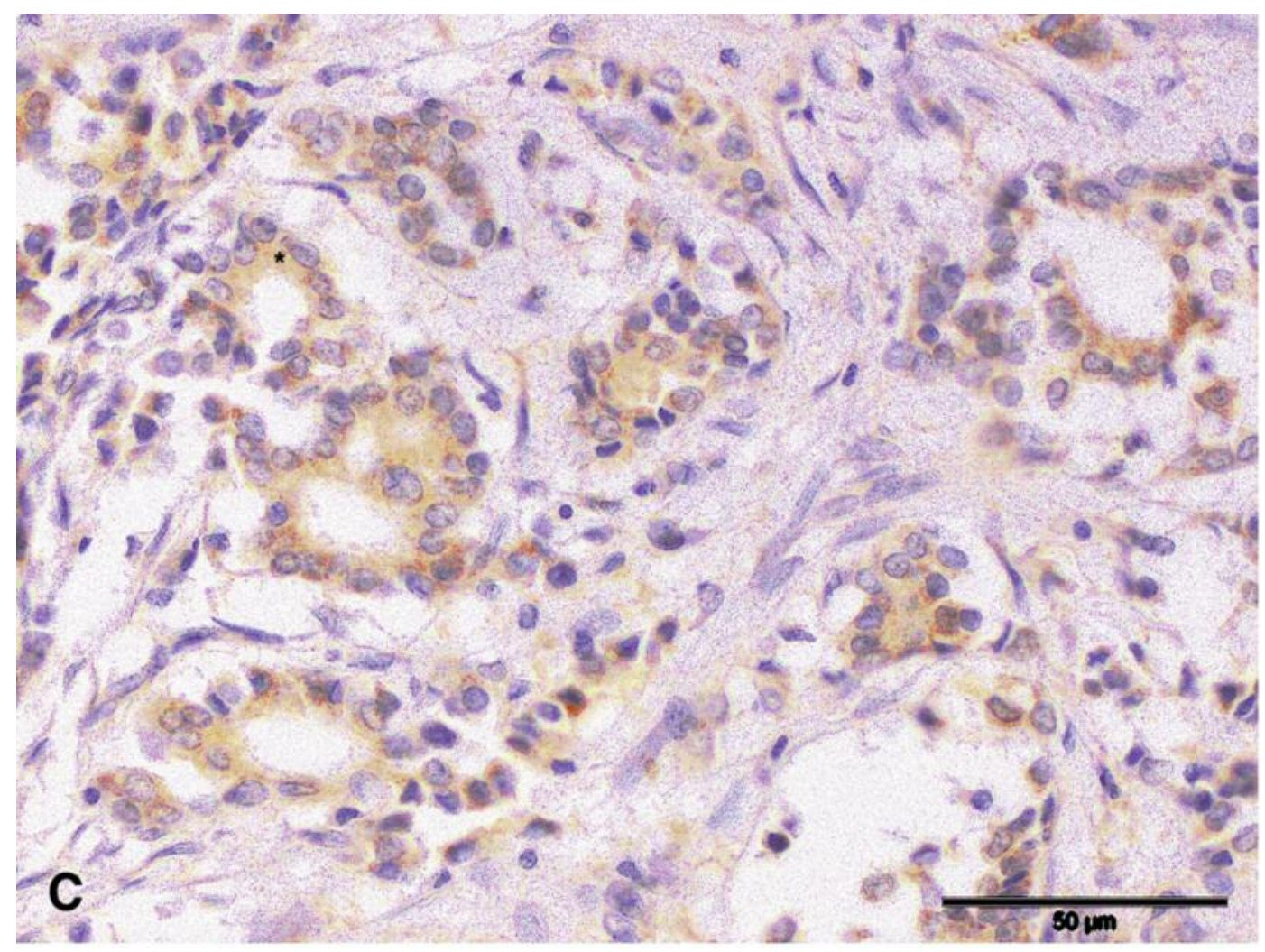

Figure 1. A-C. Pattern of cytoplasmic and nuclear expression of AR. Positive immunostaining is brown. (A) Strong (3+) nuclear and a weak (1+) to moderate $(2+)$ cytoplasmic expression, with cytoplasmic MR. (B) Moderate expression and cytoplasmic GR $\beta$ (C) Moderate expression. Cytoplasmic expression is marked with an asterisk (*) and nuclear expression with an arrow head $(\wedge)$.

expression was mostly nuclear $(97.8 \%)$; only 3 samples (2.2\%) expressed positive cytoplasmic staining (Figure 1A). Nuclear MR expression was reliably assessed in 123 (80.9\%) cases and cytoplasmic MR in 125 (82.2\%) cases. Cytoplasmic MR expression was more frequently positive than nuclear expression (Figure 1B). Cytoplasmic GR $\beta$ expression was reliably assessed in $140(92.1 \%)$ cases. There was no detectable nuclear GR $\beta$ staining in any of the samples (Figure 1C).

Correlations between $A R, M R$ and $G R \beta$ expression. Nuclear AR expression was correlated positively with cytoplasmic GR $\beta$ expression $(p<0.0050$, correlation coefficient 0.33$)$ when all patients were considered. No other significant correlations were observed. When the correlations between $\mathrm{AR}, \mathrm{MR}$ and GR $\beta$ were also assessed separately in TNBC and non-TNBC subgroups, no significant associations could be detected.

$A R, M R$ and GR $\beta$ expression and association with clinicopathological parameters. In the whole cohort, nuclear AR expression was associated with smaller tumour size $(p=0.029)$ and better differentiation $(p=0.0010)$, whereas cytoplasmic GR $\beta$ expression was associated with lower proliferation $(p=0.043)$ and cytoplasmic MR expression was associated with node-negativity $(p=0.018)$. When the traditional prognostic factors were assessed separately in the subgroups of TNBC and non-TNBC, a similar association was observed with a nuclear $\mathrm{AR}$ expression and smaller tumour size in the non-TNBC group $(p=0.024)$. In the TNBC group, nuclear $\mathrm{AR}$ expression was associated with better differentiation $(p=0.0010)$. A cytoplasmic MR expression was associated with node-negativity $(p=0.015)$, better differentiation $(p=0.017)$, and lesser proliferation $(p=0.033)$ in TNBC. When all patients were considered, AR and GR $\beta$ were associated with the non-TNBC subgroup $(p<0.0010$ for both) while MR was associated with the TNBC phenotype $(p<0.0010)$ (Table II).

$A R, M R$ and $G R \beta$ expression and their association with EMTmarkers. Nuclear AR and cytoplasmic GR $\beta$ expression were associated inversely with vimentin expression $(p<0.0010)$ when all patients were considered (Table III). In the TNBC subgroup cytoplasmic MR expression was associated with 

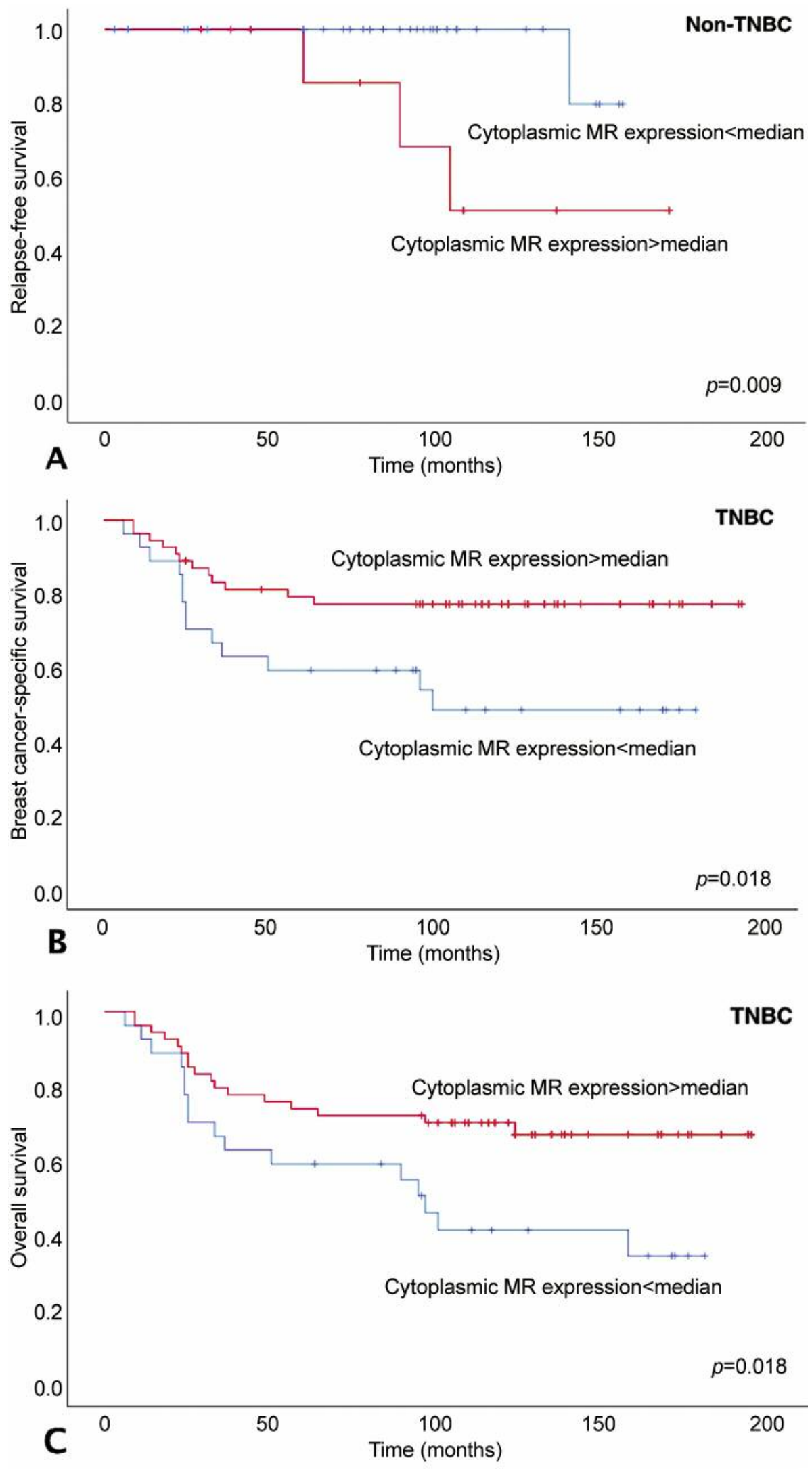

Figure 2. Continued 

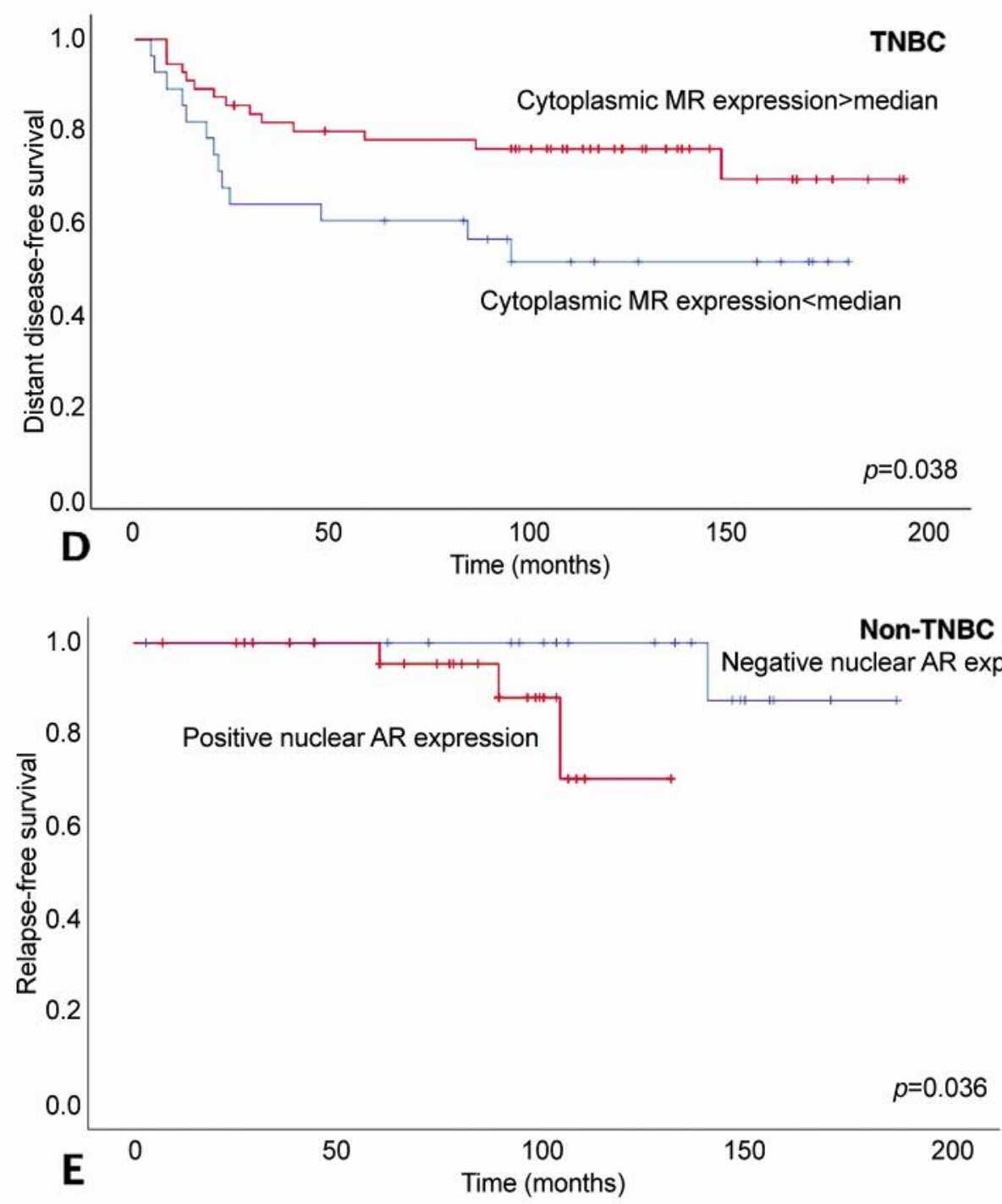

Figure 2. Cytoplasmic MR expression predicts a dismal relapse-free survival in the non-TNBC subgroup (A). Cytoplasmic MR expression predicts a better breast cancer specific survival (B), overall survival $(C)$ and distant disease-free survival $(D)$ in the patients with TNBC tumour phenotype. Nuclear AR expression was associated with a dismal relapse-free survival in the non-TNBC subgroup (E).

negative vimentin expression $(p=0.038)$ and stronger SIP1 expression $(p=0.036)$. Nuclear AR expression showed an inverse correlation with vimentin expression $(p<0.0010)$ (Table IV). Cytoplasmic GR $\beta$ expression was associated with negative expression of vimentin $(p=0.0020)$ in the non-TNBC subgroup (Table IV).

Survival analysis. An over-median cytoplasmic MR expression was associated with dismal RFS (in univariate analysis, $p=0.009$ ) in patients with non-TNBC phenotype (Figure 2A). This was confirmed in Cox regression analysis $(\mathrm{RR}=13.923 ; 95 \% \mathrm{CI}=1.071-181.045 ; p=0.044)$, when $\mathrm{T}$ - class $(\mathrm{RR}=1.664 ; 95 \% \mathrm{CI}=0.125-22.213 ; p=0.700)$ and nodal status $(\mathrm{RR}=4.834 ; 95 \% \mathrm{CI}=0.196-119.113 ; p=0.335)$ were included in the analysis. On the other hand, in patients with TNBC phenotype an over-median cytoplasmic MR expression was associated with a better BCSS, DDFS and OS in univariate analysis $(p=0.018, p=0.018$ and $p=0.038$, respectively) although this could not be confirmed in multivariate analysis (Figures 2B, C, D). Nuclear AR expression was associated with dismal RFS (in univariate analysis, $p=0.036$ ) in non-TNBC phenotype (Figure 2E). This also was not confirmed in Cox regression analysis. GR $\beta$ expression did not associate with prognosis. 
Table II. The significant 2-sided p-values of associations between AR, $M R$ and GR $\beta$ expression and traditional prognostic factors.

\begin{tabular}{|c|c|c|c|}
\hline & $\begin{array}{l}\text { Whole } \\
\text { cohort }\end{array}$ & $\begin{array}{c}\text { TNBC } \\
\text { subgroup }\end{array}$ & $\begin{array}{l}\text { Non-TNBC } \\
\text { subgroup }\end{array}$ \\
\hline \multicolumn{4}{|l|}{$\mathrm{T}(\mathrm{T} 1$ vs. T2-4) } \\
\hline AR nuclear & $p=0.029 \downarrow$ & ns & $p=0.024 \downarrow$ \\
\hline MR nuclear & ns & ns & ns \\
\hline MR cytoplasmic & ns & ns & ns \\
\hline GR $\beta$ cytoplasmic & $\mathrm{ns}$ & ns & ns \\
\hline \multicolumn{4}{|l|}{$\mathrm{N}(\mathrm{N} 0 v s . \mathrm{N} 1-3)$} \\
\hline AR nuclear & ns & ns & ns \\
\hline MR nuclear & $p=0.018 \downarrow$ & ns & ns \\
\hline MR cytoplasmic & $\mathrm{ns}$ & $p=0.015 \downarrow$ & $\mathrm{ns}$ \\
\hline GR $\beta$ cytoplasmic & ns & ns & ns \\
\hline \multicolumn{4}{|l|}{ Grade (I-II vs. III) } \\
\hline AR nuclear & $p=0.001 \downarrow$ & $p=0.001 \downarrow$ & ns \\
\hline MR nuclear & ns & ns & ns \\
\hline MR cytoplasmic & $\mathrm{ns}$ & $p=0.017 \downarrow$ & ns \\
\hline GR $\beta$ cytoplasmic & ns & ns & ns \\
\hline \multicolumn{4}{|c|}{ Ki67 (0-14\% vs. >14\%) } \\
\hline AR nuclear & ns & ns & ns \\
\hline MR nuclear & ns & ns & ns \\
\hline MR cytoplasmic & ns & $p=0.033 \downarrow$ & ns \\
\hline GR $\beta$ cytoplasmic & $p=0.043 \downarrow$ & ns & ns \\
\hline
\end{tabular}

$\downarrow$ : Inverse association; $\uparrow$ : direct association; ns: not statistically significant.

\section{Discussion}

According to our knowledge, this is the first study to evaluate MR and GR $\beta$ expression in breast cancer patients. The main result of the study was that cytoplasmic MR expression predicts worse RFS in patients with non-TNBC $\left(\mathrm{ER}^{+} / \mathrm{PR}^{+} / \mathrm{HER} 2^{-}\right)$phenotype tumours. Furthermore, our results support previous observations that SNRs interact with EMT regulation.

There is evidence indicating that MR plays a role in cancer progression and prognosis. MR expression appears to be a protective factor in both non-small cell lung cancer and colorectal cancer pathogenesis, and its expression is associated with prolonged OS in both cancers (40). In hepatocellular carcinoma MR expression has been associated with suppression of cell proliferation by metabolic modulation in vitro and also with better outcome, although only in univariate analysis (41).

The prognostic value of MR has not been previously assessed in breast cancer. Our results suggest that ER/PR expressions may have an influence on the prognostic role of $\mathrm{MR}$ in breast carcinomas. In $\mathrm{ER}^{+} / \mathrm{PR}^{+} / \mathrm{HER} 2^{-}$cancers, high cytoplasmic MR expression predicted dismal outcome in terms of local relapses. Furthermore, multivariate analysis
Table III. The significant 2-sided p-values of associations between AR, $M R$ and GR $\beta$ expression and EMT-markers in the whole patient cohort.

\begin{tabular}{lcc}
\hline & Vimentin & SIP1 \\
\hline AR nuclear & $<0.0010 \downarrow$ & $\mathrm{ns}$ \\
MR nuclear & $\mathrm{ns}$ & $\mathrm{ns}$ \\
MR cytoplasmic & $\mathrm{ns}$ & $\mathrm{ns}$ \\
GR $\beta$ cytoplasmic & $<0.0010 \downarrow$ & $\mathrm{ns}$ \\
\hline
\end{tabular}

$\downarrow$ : Inverse association; $\uparrow$ : direct association; ns: not statistically significant.

Table IV. The significant 2-sided p-values of associations between AR, $M R$ and GR $\beta$ expression and EMT-markers in the TNBC subgroup.

\begin{tabular}{lcc}
\hline & Vimentin & SIP1 \\
\hline AR nuclear & $<0.0010 \downarrow$ & $\mathrm{ns}$ \\
MR nuclear & $\mathrm{ns}$ & $\mathrm{ns}$ \\
MR cytoplasmic & $0.038 \downarrow$ & $0.036 \uparrow$ \\
GR $\beta$ cytoplasmic & $\mathrm{ns}$ & $\mathrm{ns}$ \\
\hline
\end{tabular}

$\downarrow$ : Inverse association; $\uparrow$ : direct association; ns: not statistically significant.

Table V. The significant 2-sided p-values of associations between AR, $M R$ and GR $\beta$ expression and EMT-markers in the non-TNBC subgroup.

\begin{tabular}{lcc}
\hline & Vimentin & SIP1 \\
\hline AR nuclear & $\mathrm{ns}$ & $\mathrm{ns}$ \\
MR nuclear & $\mathrm{ns}$ & $\mathrm{ns}$ \\
MR cytoplasmic & $\mathrm{ns}$ & $\mathrm{ns}$ \\
GR $\beta$ cytoplasmic & $0.022 \downarrow$ & $\mathrm{ns}$ \\
\hline
\end{tabular}

$\downarrow$ : Inverse association; $\uparrow$ : direct association; ns: not statistically significant.

indicated that their prognostic value even exceeded that of tumour size and nodal status which are conventionally considered the most powerful factors. Along with genomic (nuclear) mechanisms, MR plays vital roles in regulating signalling pathways in the cytoplasm $(11,42)$. The exact mechanism of this rapid secondary messenger signaling or protein kinase activation cascades remains to be elucidated, but they may be related to the current results since nuclear MR has not previously shown to have any prognostic value. Conversely, in TNBCs. MR appeared to predict prolonged OS, BCSS and DDFS, which nevertheless could not be confirmed in multivariate analysis. In line with this, cytoplasmic MR expression was also associated with low 
grade, slow proliferation and negative nodal status in the TNBC subgroup. MR expression was significantly more prominent in the patients with TNBC compared with the non-TNBC group.

In the current study, relapses located in ipsilateral or contralateral axilla, scar or breast were recorded as local relapses. MR may promote only local invasion in $\mathrm{ER}^{+} / \mathrm{PR}^{+} / \mathrm{HER} 2^{-}$cancers or may even be linked to radiotherapy resistance. Due to very poor characterization of MR in cancers, and especially in breast cancer, there is no previous data to support interaction between ER and MR in breast carcinogenesis. However, it has been suspected that MR, like the other members of the nuclear superfamily of transcription factors, would have a role in the modulation of EMT, although this has not been thoroughly studied (12). In kidney cells, aldosterone exposure induces EMT via MRmediated mitochondrial-originated, ROS-dependent ERK1/2 activation $(33,43,44)$. Aldosterone also mimics PR-like effects in breast cancer in vitro, inducing focal adhesion and growth inhibition (12). We did not find any association with MR expression and any of EMT marker expressions in the non-TNBC group. In TNBC patients, higher MR expression was associated with increased vimentin, a cytoskeleton protein, which is considered a marker of EMT. This may partly explain the tendency of poorer survival and distant disease control in TNBC patients. The association of vimentin with ER negative phenotype in breast cancer has been reported decades ago (31). Another possible role for MR in cancer biology could be related to micromilieu and oxidative stress. Activated MR enhances inflammation and leads to reactive oxygen species generation by inducing NADPH oxidase (45). This could result in vascular remodeling via an enhanced expression of the multiple genes involved, suggesting that MR activation favors pathogenesis (46).

The role of GCs as well as of GR in cancer biology incorporates a wide range of cellular mechanisms (47). The physiologically dominant isoform, GR $\alpha$, has an ERindependent prognostic role in breast cancer (23). GR $\beta$ has previously attracted only cursory attention in breast cancer literature, but its expression has been reported in ER-positive MCF-7 cells (48). Data from other malignancies suggest that GR $\beta$ enhances in vitro migration in bladder cancer cell lines, and the proliferation of glioma and prostate cancer cells (49$51)$. We found an inverse association between GR $\beta$ and the EMT-marker vimentin in $\mathrm{ER}^{+} / \mathrm{PR}^{+} / \mathrm{HER} 2^{-}$tumours. In line with this, GR $\beta$ was associated with a slightly lower proliferation rate. According to our knowledge, GR $\beta$ protein expression has not been previously evaluated in any cancer.

$\mathrm{AR}$ is by far the best characterized SNR in breast cancer. In our study, nuclear AR expression was associated with worse RFS in non-TNBC phenotypes, although we could not confirm this association in multivariate analysis. Søiland et al have previously measured AR cytoplasmic expression with the dextran-coated charcoal method and reported that it predicts prolonged RFS in patients with high AR levels (52). Some meta-analyses have demonstrated longer disease-free survival (DFS) (but not overall survival) in AR-positive breast cancers $(53,54)$. We were unable to replicate this result in the current study, which is not very surprising since the effect of AR on survival in previous studies has been quite small and the size of our sample was quite limited. On the other hand, in our whole cohort, AR was associated with a smaller tumour size and lower tumour grade, confirming recent findings $(55,56)$. The possible therapeutic role of AR in breast cancer is currently under evaluation. Regarding EMT markers, we observed strong suppression in vimentin in patients with high AR expression and the TNBC phenotype. The role of AR and EMT is not explicitly clear, it is possible that dihydrotestosterone, an AR ligand, reduces E-cadherin, triggers EMT and promotes tumour metastasis (56). High AR expression, detected by immunohistochemistry, may be the result of high $\mathrm{AR}$ stability $(57,58)$. Finally, in line with previous literature, AR was prominently overexpressed in non-TNBC breast cancers (54).

Our study has some weaknesses. The prognostic role of MR expression needs to be viewed in proportion with the relatively small number of cases in the non-TNBC group, although the result was indeed confirmed in multivariate analysis. In the future, we would welcome a study which will combine immunostaining of GR $\alpha$ and GR $\beta$ to clarify the role of GR $\beta$ expression in breast cancer, since the biochemical pathways of GR $\alpha$ are quite well-known. Cytoplasmic MR expression may be a new prognostic marker for non-metastatic breast cancer, but additional research is needed to establish its role in breast cancer biology. In future studies, receptors, ligands and ligand-receptor interactions should be evaluated.

We conclude that cytoplasmic MR protein expression is tightly associated with worse RFS, independent of tumour size and nodal status, if the primary tumour has $\mathrm{ER}^{+} / \mathrm{PR}^{+} / \mathrm{HER} 2^{-}$phenotype. This is likely to be mediated by a mechanism other than EMT. Whether poor local relapse control is related to the effect of aldosterone or another ligand of MR or radioresistance, remains to be evaluated. The current results encourage clarification of the possible prognostic value of MR expression in a prospective study.

\section{Conflicts of Interest}

The Authors report no conflicts of interest regarding this study.

\section{Authors' Contributions}

All Authors contributed to the study design and conception. AJä, $\mathrm{KMH}$ and $\mathrm{AJu}$ collected the data on Oulu University Hospital patients. YS and PA collected the data on Kuopio University Hospital patients. Immunohistochemical stainings were coordinated and examined by KMH and YS. PK and AJä were responsible for 
assessing statistical analyses. AJä and PK were major contributors in writing the manuscript. All Authors provided comments on drafts of the manuscript. All Authors read and approved the final manuscript.

\section{Acknowledgements}

The Authors acknowledge the help of laboratory technicians Mrs. Erja Tomperi and Mrs. Riitta Vuento for their expertise and work with the AR, MR and GR $\beta$ immunohistochemistry.

\section{References}

1 Metzger-Filho O, Tutt A, de Azambuja E, Saini KS, Viale G, Loi S, Bradbury I, Bliss JM, Azim HA, Ellis P, Di Leo A, Baselga J, Sotiriou C and Piccart-Gebhart M: Dissecting the heterogeneity of triple-negative breast cancer. J Clin Oncol 30: 1879-1887, 2012. PMID: 22454417. DOI: 10.1200/JCO.2011.38.2010

2 De Bosscher K: Selective Glucocorticoid Receptor modulators. J Steroid Biochem Mol Biol 120: 96-104, 2010. PMID: 20206690. DOI: 10.1016/j.jsbmb.2010.02.027

3 Conzen SD: Minireview: nuclear receptors and breast cancer. Mol Endocrinol 22: 2215-2228, 2008. PMID: 18417735. DOI: 10.1210/me.2007-0421

4 Luo X, Shi YX, Li ZM and Jiang WQ: Expression and clinical significance of androgen receptor in triple negative breast cancer. Chin J Cancer 29: 585-590, 2010. PMID: 20507730.

5 Niemeier LA, Dabbs DJ, Beriwal S, Striebel JM and Bhargava $\mathrm{R}$ : Androgen receptor in breast cancer: expression in estrogen receptor-positive tumors and in estrogen receptor-negative tumors with apocrine differentiation. Mod Pathol 23: 205-212, 2010. PMID: 19898421. DOI: 10.1038/modpathol.2009.159

6 He J, Peng R, Yuan Z, Wang S, Peng J, Lin G, Jiang X and Qin $T$ : Prognostic value of androgen receptor expression in operable triple-negative breast cancer: a retrospective analysis based on a tissue microarray. Med Oncol 29: 406-410, 2012. PMID: 21264529. DOI: 10.1007/s12032-011-9832-0

7 Park S, Koo J, Park HS, Kim J-H, Choi S-Y, Lee JH, Park B-W and Lee KS: Expression of androgen receptors in primary breast cancer. Ann Oncol 21: 488-492, 2010. PMID: 19887463. DOI: 10.1093/annonc/mdp510

8 Albiston AL, Smith RE, Obeyesekere VR and Krozowski ZS: Cloning of the 11 beta HSD type II enzyme from human kidney. Endocr Res 21: 399-409, 1995. PMID: 7588404.

9 Krozowski Z, Albiston AL, Obeyesekere VR, Andrews RK and Smith RE: The human 11 $\beta$-hydroxysteroid dehydrogenase type II enzyme: Comparisons with other species and localization to the distal nephron. J Steroid Biochem Mol Biol 55: 457-464, 1995. PMID: 8547170. DOI: 10.1016/0960-0760(95)00194-8

10 Galigniana MD, Erlejman AG, Monte M, Gomez-Sanchez C and Piwien-Pilipuk G: The hsp90-FKBP52 complex links the mineralocorticoid receptor to motor proteins and persists bound to the receptor in early nuclear events. Mol Cell Biol 30: 12851298, 2010. PMID: 20038533. DOI: 10.1128/MCB.01190-09

11 Nishi M, Ogawa H, Ito T, Matsuda K-I and Kawata M: Dynamic changes in subcellular localization of mineralocorticoid receptor in living cells: In comparison with glucocorticoid receptor using dual-color labeling with green fluorescent protein spectral variants. Mol Endocrinol 15: 1077-1092, 2001. PMID: 11435609. DOI: $10.1210 /$ mend.15.7.0659
12 Leo JCL, Guo C, Woon CT, Aw SE and Lin VCL: Glucocorticoid and mineralocorticoid cross-talk with progesterone receptor to induce focal adhesion and growth inhibition in breast cancer cells. Endocrinology 145: 1314-1321, 2004. PMID: 14617569. DOI: 10.1210/en.2003-0732

13 Meinel S, Ruhs S, Schumann K, Strätz N, Trenkmann K, Schreier B, Grosse I, Keilwagen J, Gekle M and Grossmann C: Mineralocorticoid receptor interaction with SP1 generates a new response element for pathophysiologically relevant gene expression. Nucleic Acids Res 41: 8045-8060, 2013. PMID: 23821666. DOI: $10.1093 / \mathrm{nar} / \mathrm{gkt} 581$

14 Sasano H, Frost AR, Saitoh R, Matsunaga G, Nagura H, Krozowski ZS and Silverberg SG: Localization of mineralocorticoid receptor and 11 beta-hydroxysteroid dehydrogenase type II in human breast and its disorders. Anticancer Res 17: 2001-2007, 1997. PMID: 9216657.

15 Hollenberg SM, Weinberger C, Ong ES, Cerelli G, Oro A, Lebo R, Brad Thompson E, Rosenfeld MG and Evans RM: Primary structure and expression of a functional human glucocorticoid receptor cDNA. Nature 318: 635-641, 1985. PMID: 2867473. DOI: $10.1038 / 318635 \mathrm{a} 0$

16 Duma D, Jewell CM and Cidlowski JA: Multiple glucocorticoid receptor isoforms and mechanisms of post-translational modification. J Steroid Biochem Mol Biol 102: 11-21, 2006. PMID: 17070034. DOI: 10.1016/j.jsbmb.2006.09.009

17 Kino T and Chrousos GP: Glucocorticoid and mineralocorticoid resistance/hypersensitivity syndromes. J Endocrinol 169: 437445, 2001. PMID: 11375113. DOI: 10.1677/joe.0.1690437

18 Chrousos GP: The hypothalamic-pituitary-adrenal axis and immune-mediated inflammation. N Engl J Med 332: 1351-1363, 1995. PMID: 7715646. DOI: 10.1056/NEJM199505183322008

19 Kino T, Su YA and Chrousos GP: Human glucocorticoid receptor isoform beta: recent understanding of its potential implications in physiology and pathophysiology. Cell Mol Life Sci 66: 34353448, 2009. PMID: 19633971. DOI: 10.1007/s00018-009-0098-z

20 Nwaneri AC, McBeth L and Hinds TD: Sweet-P inhibition of glucocorticoid receptor $\beta$ as a potential cancer therapy. Cancer Cell Microenviron 3: 3, 2016. PMID: 27468424.

21 Abduljabbar R, Negm OH, Lai CF, Jerjees DA, Al-Kaabi M, Hamed MR, Tighe PJ, Buluwela L, Mukherjee A, Green AR, Ali S, Rakha EA and Ellis IO: Clinical and biological significance of glucocorticoid receptor (GR) expression in breast cancer. Breast Cancer Res Treat 150: 335-346, 2015. PMID: 25762479. DOI: $10.1007 / \mathrm{s} 10549-015-3335-1$

22 Vilasco M, Communal L, Mourra N, Courtin A, Forgez P and Gompel A: Glucocorticoid receptor and breast cancer. Breast Cancer Res Treat 130: 1-10, 2011. PMID: 21818591. DOI: 10.1007/s10549-011-1689-6

23 Pan D, Kocherginsky $M$ and Conzen SD: Activation of the glucocorticoid receptor is associated with poor prognosis in estrogen receptor-negative breast cancer. Cancer Res 71: 6360-6370, 2011. PMID: 21868756. DOI: 10.1158/0008-5472.CAN-11-0362

24 Charmandari E, Chrousos GP, Ichijo T, Bhattacharyya N, Vottero A, Souvatzoglou E and Kino T: The human glucocorticoid receptor (hGR) beta isoform suppresses the transcriptional activity of hGRalpha by interfering with formation of active coactivator complexes. Mol Endocrinol 19: 52-64, 2005. PMID: 15459252. DOI: $10.1210 /$ me .2004-0112

25 de Castro M, Elliot S, Kino T, Bamberger C, Karl M, Webster $\mathrm{E}$ and Chrousos GP: The non-ligand binding beta-isoform of the 
human glucocorticoid receptor (hGR beta): tissue levels, mechanism of action, and potential physiologic role. Mol Med 2: 597-607, 1996. PMID: 8898375

26 Oakley RH, Sar M and Cidlowski JA: The human glucocorticoid receptor beta isoform. Expression, biochemical properties, and putative function. J Biol Chem 271: 9550-9559, 1996. PMID: 8621628. DOI: $10.1074 / j b c .271 .16 .9550$

27 Soini Y, Tuhkanen H, Sironen R, Virtanen I, Kataja V, Auvinen P, Mannermaa A and Kosma VM: Transcription factors zeb1, twist and snai1 in breast carcinoma. BMC Cancer 11: 73, 2011. PMID: 21324165. DOI: 10.1186/1471-2407-11-73

28 Remacle JE, Kraft H, Lerchner W, Wuytens G, Collart C, Verschueren K, Smith JC and Huylebroeck D: New mode of DNA binding of multi-zinc finger transcription factors: deltaEF1 family members bind with two hands to two target sites. EMBO J 18: 5073-5084, 1999. PMID: 10487759. DOI: 10.1093/emboj/ 18.18 .5073

29 Kim T, Veronese A, Pichiorri F, Lee TJ, Jeon Y-J, Volinia S, Pineau P, Marchio A, Palatini J, Suh S-S, Alder H, Liu C-G, Dejean A and Croce CM: p53 regulates epithelial-mesenchymal transition through microRNAs targeting ZEB1 and ZEB2. J Exp Med 208: 875-883, 2011. PMID: 21518799. DOI: 10.1084/jem.20110235

30 Vandewalle C, Comijn J, De Craene B, Vermassen P, Bruyneel E, Andersen H, Tulchinsky E, Van Roy $F$ and Berx G: SIP1/ZEB2 induces EMT by repressing genes of different epithelial cell-cell junctions. Nucleic Acids Res 33: 6566-6578, 2005. PMID: 16314317. DOI: 10.1093/nar/gki965

31 Cattoretti G, Andreola S, Clemente C, D'Amato L and Rilke F: Vimentin and 553 expression on epidermal growth factor receptorpositive, oestrogen receptor-negative breast carcinomas. Br J Cancer 57: 353-357, 1988. PMID: 3291921. DOI: 10.1038/bjc.1988.81

32 Karihtala P, Auvinen P, Kauppila S, Haapasaari K-M, JukkolaVuorinen A and Soini Y: Vimentin, zeb1 and Sip1 are up-regulated in triple-negative and basal-like breast cancers: association with an aggressive tumour phenotype. Breast Cancer Res Treat 138: 81-90, 2013. PMID: 23412770. DOI: 10.1007/s10549-013-2442-0

33 Voutsadakis I: Epithelial-mesenchymal transition (EMT) and regulation of EMT factors by steroid nuclear receptors in breast cancer: A review and in silico investigation. J Clin Med 5: 11, 2016. PMID: 26797644. DOI: 10.3390/jcm5010011

34 Truong TH and Lange CA: Deciphering steroid receptor crosstalk in hormone-driven cancers. Endocrinology 159: 38973907, 2018. PMID: 30307542. DOI: 10.1210/en.2018-00831

35 Amin MB, Greene FL, Edge SB, Compton CC, Gershenwald JE, Brookland RK, Meyer L, Gress DM, Byrd DR and Winchester DP: The eighth edition AJCC cancer staging manual: Continuing to build a bridge from a population-based to a more "personalized" approach to cancer staging. CA Cancer J Clin 67: 93-99, 2017. PMID: 28094848. DOI: 10.3322/caac.21388

36 Lakhani SR, Ellis IO, Schnitt SJ, Tan PH and van der Vijver MJ: WHO Classification of Tumours. Volume 4. Lyon, International Agency for Research on Cancer, 2012.

37 Karihtala P, Mäntyniemi A, Kang SW, Kinnula VL and Soini Y: Peroxiredoxins in breast carcinoma. Clin Cancer Res 9: 34183424, 2003. PMID: 12960131.

38 Isola J, Tanner M, Forsyth A, Cooke TG, Watters AD and Bartlett JMS: Interlaboratory comparison of HER-2 oncogene amplification as detected by chromogenic and fluorescence in situ hybridization. Clin Cancer Res 10: 4793-4798, 2004. PMID: 15269154. DOI: 10.1158/1078-0432.CCR-0428-03
39 Specht E, Kaemmerer D, Sänger J, Wirtz RM, Schulz S and Lupp A: Comparison of immunoreactive score, HER2/ neu score and $\mathrm{H}$ score for the immunohistochemical evaluation of somatostatin receptors in bronchopulmonary neuroendocrine neoplasms. Histopathology 67: 368-377, 2015. PMID: 25641082. DOI: $10.1111 /$ his.12662

40 Jeong Y, Xie Y, Xiao G, Behrens C, Girard L, Wistuba II, Minna JD and Mangelsdorf DJ: Nuclear receptor expression defines a set of prognostic biomarkers for lung cancer. PLoS Med 7: e1000378, 2010. PMID: 21179495. DOI: 10.1371/journal.pmed. 1000378

41 Nie H, Li J, Yang XM, Cao QZ, Feng MX, Xue F, Wei L, Qin W, Gu J, Xia Q and Zhang Z-G: Mineralocorticoid receptor suppresses cancer progression and the Warburg effect by modulating the miR-338-3p-PKLR axis in hepatocellular carcinoma. Hepatology 62: 1145-1159, 2015. PMID: 26082033. DOI: $10.1002 /$ hep. 27940

42 Pearce D, Náray-Fejes-Tóth A and Fejes-Tóth G: Determinants of subnuclear organization of mineralocorticoid receptor characterized through analysis of wild type and mutant receptors. J Biol Chem 277: 1451-1456, 2002. PMID: 11677231. DOI: $10.1074 /$ jbc.M105966200

43 Diah S, Zhang G-X, Nagai Y, Zhang W, Gang L, Kimura S, Rw M, Hamid A, Tamiya T, Nishiyama A and Hitomi H: Aldosterone induces myofibroblastic transdifferentiation and collagen gene expression through the Rho-kinase dependent signaling pathway in rat mesangial cells. Exp Cell Res 314: 3654-3662, 2008. PMID: 18929559. DOI: 10.1016/j.yexcr.2008.09.018

44 Zhang A, Jia Z, Guo X and Yang T: Aldosterone induces epithelial-mesenchymal transition via ROS of mitochondrial origin. Am J Physiol Physiol 293: F723-F731, 2007. PMID: 17596522. DOI: 10.1152/ajprenal.00480.2006

45 Nakano S, Kobayashi N, Yoshida K, Ohno T and Matsuoka H: Cardioprotective mechanisms of spironolactone associated with the angiotensin-converting enzyme/epidermal growth factor receptor/extracellular signal-regulated kinases, $\mathrm{NAD}(\mathrm{P}) \mathrm{H}$ oxidase/lectin-like oxidized low-density lipoprotein receptor-1, and rho-kinase pathways in aldosterone/salt-induced hypertensive rats. Hypertens Res 28: 925-936, 2005. PMID: 16555582. DOI: 10.1291/hypres 28.925

46 Stas S, Whaley-Connell A, Habibi J, Appesh L, Hayden MR, Karuparthi PR, Qazi M, Morris EM, Cooper SA, Link CD, Stump C, Hay M, Ferrario C and Sowers JR: Mineralocorticoid receptor blockade attenuates chronic overexpression of the reninangiotensin-aldosterone system stimulation of reduced nicotinamide adenine dinucleotide phosphate oxidase and cardiac remodeling. Endocrinology 148: 3773-3780, 2007. PMID: 17494996. DOI: 10.1210/en.2006-1691

47 Mcnamara KM, Kannai A and Sasano H: Possible roles for glucocorticoid signalling in breast cancer. Mol Cell Endocrinol 466: 38-50, 2018. PMID: 28687451. DOI: 10.1016/j.mce. 2017.07.004

48 Piotrowska $\mathrm{H}$ and Jagodzinski PP: Glucocorticoid receptor $\alpha$ and $\beta$ variant expression is associated with $\mathrm{ASF} / \mathrm{SF} 2$ splicing factor upregulation in HT-29 colon cancer and MCF-7 breast carcinoma cells. Arch Med Res 40: 156-162, 2009. PMID: 19427965. DOI: 10.1016/j.arcmed.2009.02.004

49 Wang Q, Lu PH, Shi ZF, Xu YJ, Xiang J, Wang YX, Deng LX, Xie P, Yin Y, Zhang B, Mu HJ, Qiao WZ, Cui H and Zou J: Glucocorticoid receptor $\beta$ acts as a co-activator of T-Cell Factor 
4 and enhances glioma cell proliferation. Mol Neurobiol 52: 11061118, 2015. PMID: 25301232. DOI: 10.1007/s12035-014-8900-9

50 McBeth L, Nwaneri AC, Grabnar M, Demeter J, Nestor-Kalinoski A and Hinds TD Jr.: Glucocorticoid receptor beta increases migration of human bladder cancer cells. Oncotarget 7: 2731327324, 2016. PMID: 27036026. DOI: 10.18632/oncotarget.8430

51 Ligr M, Li Y, Logan SK, Taneja S, Melamed J, Lepor H, Garabedian MJ and Lee P: Mifepristone inhibits GR $\beta$ coupled prostate cancer cell proliferation. J Urol 188: 981-988, 2012. PMID: 22819113. DOI: 10.1016/j.juro.2012.04.102

52 Søiland H, Kørner H, Skaland I, Janssen EAM, Gudlaugsson E, Varhaug JE, Baak JPA and Søreide JA: Prognostic relevance of androgen receptor detection in operable breast cancer. J Surg Oncol 98: 551-558, 2008. PMID: 18937259. DOI: 10.1002/jso.21156

53 Wang C, Pan B, Zhu H, Zhou Y, Mao F, Lin Y, Xu Q and Sun $\mathrm{Q}$ : Prognostic value of androgen receptor in triple negative breast cancer: A meta-analysis. Oncotarget 7: 46482-46491, 2016. PMID: 27374089. DOI: 10.18632/oncotarget.10208

54 Vera-Badillo FE, Templeton AJ, de Gouveia P, Diaz-Padilla I, Bedard PL, Al-Mubarak M, Seruga B, Tannock IF, Ocana A and Amir E: Androgen receptor expression and outcomes in early breast cancer: A systematic review and meta-analysis. JNCI J Natl Cancer Inst 106: djt319-djt319, 2014. PMID: 24273215. DOI: $10.1093 /$ jnci/djt319

55 Gerratana L, Basile D, Buono G, De Placido S, Giuliano M, Minichillo S, Coinu A, Martorana F, De Santo I, Del Mastro L, De Laurentiis M, Puglisi F and Arpino G: Androgen receptor in triple negative breast cancer: A potential target for the targetless subtype. Cancer Treat Rev 68: 102-110, 2018. PMID: 29940524. DOI: $10.1016 /$ j.ctrv.2018.06.005
56 Kensler KH, Regan MM, Heng YJ, Baker GM, Pyle ME, Schnitt SJ, Hazra A, Kammler R, Thürlimann B, Colleoni M, Viale G, Brown $\mathrm{M}$ and Tamimi RM: Prognostic and predictive value of androgen receptor expression in postmenopausal women with estrogen receptor-positive breast cancer: results from the Breast International Group Trial 1-98. Breast Cancer Res 21: 30, 2019. PMID: 30795773. DOI: 10.1186/s13058-019-1118-z

57 Feng J, Li L, Zhang N, Liu J, Zhang L, Gao H, Wang G, Li Y, Zhang Y, Li X, Liu D, Lu J and Huang B: Androgen and AR contribute to breast cancer development and metastasis: an insight of mechanisms. Oncogene 36: 2775-2790, 2017. PMID: 27893717. DOI: $10.1038 /$ onc.2016.432

58 Liu YN, Liu Y, Lee HJ, Hsu YH and Chen JH: Activated androgen receptor downregulates E-cadherin gene expression and promotes tumor metastasis. Mol Cell Biol 28: 7096-7108, 2008. PMID: 18794357. DOI: 10.1128/MCB.00449-08
Received August 27, 2019

Revised September 19, 2019

Accepted September 23, 2019 